\title{
Mixed-method study on the satisfaction of a high-fidelity simulation program in a sample of nursing-degree students
}

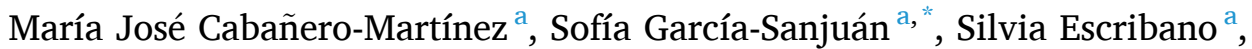 \\ Manuel Fernández-Alcántara ${ }^{\mathrm{b}}$, José Ramón Martínez-Riera ${ }^{\mathrm{c}}$, Rocio Juliá-Sanchís ${ }^{\mathrm{a}}$ \\ ${ }^{a}$ Nursing Department, Health Sciences Faculty, University of Alicante, San Vicente del Raspeig, Alicante s/n-03690, P.O.B: 99, Spain \\ ${ }^{\mathrm{b}}$ Health Psychology Department, Health Sciences Faculty, University of Alicante, San Vicente del Raspeig, Alicante s/n-03690, P.O.B: 99, Spain \\ ${ }^{\mathrm{c}}$ Department of Community Intervention and History, Health Sciences Faculty, University of Alicante, San Vicente del Raspeig, Alicante s/n-03690, P.O.B: 99, Spain
}

\section{A R T I C L E I N F O}

\section{Keywords:}

High-fidelity simulation

Nursing

Standardized patient

Satisfaction

Undergraduate

\begin{abstract}
A B S T R A C T
Background: Training emotionally complex communication skills with standardized patients brings realism to simulation scenarios, and moreover, is associated with high levels of satisfaction among the students.

Objectives: (1) To measure the satisfaction of nursing students and factors related to their satisfaction and (2) to explore the effects perceived by nursing students after having a high-fidelity simulation training program using standardized patients.

Design and participants: Mixed design. Pre-post quasi-experimental phase in which the Satisfaction Scale Questionnaire with High-Fidelity Clinical Simulation was administered in 156 students; a second, semi-structured interview qualitative phase was completed by 11 students.

Results: Nursing students showed high satisfaction scores. The scores for utility and communication were correlated with the students' attitudes towards communication. In the second phase, two main themes and four sub-themes emerged.

Conclusions: Teachers could implement high-fidelity simulation programs with standardized patients for training emotionally complex communication skills to nursing students. These programs allow students to participate in their own learning processes and help them to feel motivated and satisfied about the usefulness of their learning experiences.
\end{abstract}

\section{Introduction}

Simulation in educational contexts refers to a situation that tries to represent real clinical practice through scenarios with different degrees of fidelity. The use of simulated scenarios allows various clinical skills to be repeatedly trained in a safe environment (Alsaad et al., 2017; Yuan et al., 2012) until an optimal learning level is reached and critical and reflective analysis skills are developed (Hegland et al., 2017; RaurellTorredà et al., 2020).

High-fidelity environments involve the use of advanced technologies such as highly interactive mannequins (Sarabia-Cobo et al., 2016) which provide realistic physiological responses (Cant and Cooper, 2010). Standardized patients are individuals, students, or actors trained to represent patients in a realistic and consistent way (Cant and Cooper, 2010). Standardized patients bring realism to the scenarios presented in communication skills training (Willhaus, 2016) and are especially important for training emotionally-complex situations (Oh et al., 2015) which would otherwise be difficult to implement because of the lack of effective alternative methodologies (Kim et al., 2016). Over the last decade, the use of standardized patients for training communication skills in nursing students has considerably increased, especially in the areas of oncology, mental health, and palliative care (MacLean et al., 2017).

Evaluating simulation programs using standardized patients provides us with relevant information on their sustainability and viability and allows us to look for opportunities for improvement (Kirkpatrick and Kirkpatrick, 2006). Such evaluations can be undertaken at the following levels: level 1: 'reaction' (e.g., the satisfaction levels of the participants); level 2: 'learning' (e.g., the knowledge and skills acquired); level 3: 'behavior' (e.g., the application of acquired knowledge);

\footnotetext{
* Corresponding author.

E-mail addresses: Mariajose.cabanero@ua.es (M.J. Cabañero-Martínez), sofia.garcia@gcloud.ua.es (S. García-Sanjuán), silvia.escribano@ua.es (S. Escribano), mfernandeza@ua.es (M. Fernández-Alcántara), jr.martinez@ua.es (J.R. Martínez-Riera), rjulia@ua.es (R. Juliá-Sanchís).
} 
and level 4: 'outcome' (e.g., student quality of life; Kirkpatrick \& Kirkpatrick, 2006). This present work focused on student satisfaction as a reaction metric (Fey and Jenkins, 2015) and also inquired into the perceived purposes and effects the program had on student learning in relation to satisfaction.

Several studies have showed had high satisfaction scores for simulation program on communication with standardized patients (Hsu et al., 2015), in applied situations where these skills were a priority such as in oncology (Jang et al., 2019) or mental health (Goh et al., 2016) contexts, or in programs focused on technical-skills training (LuctkarFlude et al., 2012). However, Oh et al. (2015) in their meta-analysis about the effects of simulation-based learning using standardized patients in nursing students, did not show a significant improvement in the students' perceived learning satisfaction, perhaps because of the high heterogeneity of the group included in the review. Therefore, continued work with larger samples to investigate nursing students' satisfaction with these programs and to explore what they are most and least satisfied with, is still required. Accordingly, Goh et al. (2016) concluded that such studies should explore the perceived effects and positive benefits identified by students during their clinical placements, to allow researchers to learn how simulation programs impact clinical practice in these students.

Indeed, nursing student satisfaction levels are considered an important factor that facilitate learning because they are related to greater student participation (Lapkin et al., 2010), motivation (Walker et al., 2016), and can improve their performance and learning outcomes (Bremner et al., 2006; Mullan and Kothe, 2010). However, few studies have analyzed the relationship between satisfaction and variables (such as the topics they study or their methodology) as these relate to simulation programs. Thus, studies that have examined these variables show that student satisfaction is related both to students' knowledge of the theoretical aspects of the simulated case before engaging in it (Calamassi et al., 2016), as well as their active participation during the experience (Olaussen et al., 2020). Therefore, better knowledge of the factors related to satisfaction, will help us to design effective scenario-based simulation programs (Olaussen et al., 2020) with standardized patients.

\section{Aims}

The objectives of this study were to take a mixed method approach to (1) measure the satisfaction of nursing students and factors related to their satisfaction and (2) to explore the effects perceived by nursing students after having a high-fidelity simulation training program using standardized patients. Thus, we asked the following research questions: (1) What is the level of nursing student satisfaction after completing a high-fidelity simulation program using standardized patients? (2) What variables that form a direct part of the program topic (communication skills) are related to satisfaction? (3) What effects do nursing students perceive as being derived from the high-fidelity simulation program using standardized patients?

\section{Methods}

\subsection{Study design and participants}

We carried out a mixed-methods study, implemented in two phases. The first phase was quantitative (quasi-experimental design) and implemented a high-fidelity simulation program with standardized patients. All eligible participants $(n=205)$, who were fourth-year students in the nursing undergraduate course during the academic period 2019-2020 at the University of XXXX, completed the simulation program between September and December 2019. The whole sample $(N=$ 205) participated in the simulation program and were divided into 12 laboratory practice groups (A-L) at random. Each group (comprising 17-18 students) divided themselves up freely into a total of 6 subgroups, each with 2-3 members. Both the group and sub-group distributions remained unaltered throughout the intervention. A total of 156 of all the eligible sample completed the post-intervention questionnaire (loss rate $=24.27 \%$ ).

The second phase was qualitative and was carried out by telephone as a semi-structured interview. All the students who were contacted for the telephone interview $(n=11)$ voluntarily agreed to participate.

\subsection{Intervention}

The main objective of the simulation program was to train the students in the use of effective healthcare communication skills in difficult situations such as in the context of chronicity at different periods of patients' lives and/or end-of-life care. The program was structured into 8 sessions, each lasting $2.5 \mathrm{~h}$. The first two sessions were preparation sessions prior to the simulated scenario training and were designed to introduce the students to the educational intervention and scenarios, generate a known and safe environment for the groups by performing group dynamics, and to organize the sub-groups. The high-fidelity simulation with standardized patients was implemented in the 6 following sessions. We trained a total of 12 different scenarios, which the following contents were trained: grief $(n=3)$, decision making and coping with difficult situations $(n=3)$, state of severe confusion in the context of chronicity $(n=2)$, bad news $(n=1)$, pact of silence $(n=1)$, pain management $(n=1)$, and end of life $(n=1)$. Therefore, every day the groups trained two different cases.

Each group (A-L) completed all the program scenarios (8 sessions and a total of $20 \mathrm{~h}$ ). Therefore, each sub-group $(n=6)$ actively participated in a total of 4 different simulation scenarios and observed the other simulations (20/24) for their group (A-L), actively participating in the debriefing. The session structure for each scenario was: predebriefing, presentation of the case by the students, simulation, and a structured group debriefing during the simulation session, as suggested elsewhere in the literature (Lee et al., 2020, Webster, 2014),

A total of 8 teachers participated, and they had all received a 4-h training program in the standardized training procedure that should be followed. Three qualified actors who were all experts in improvisation participated as the standardized patients. They received information and details about the appropriate interventions for each scenario so that they could prepare beforehand.

\subsection{Instruments and other variables}

We developed a questionnaire that included the following sociodemographic data: sex, age, and nationality (Spanish/other). In addition, information related to prior training in communication skills was collected via two questions: "Have you received training in social/ communication skills during your nursing degree training?" and "Have you received training outside your nursing degree in social/communication skills?"

The students' attitude towards communication was evaluated through the Spanish version (Escribano et al., 2021) of the Attitudes Towards Medical Communication Scale (Langille et al., 2001), which had an adequate internal consistency of 0.74 in the original version. The Spanish adaptation contains 11 items which are measured on a Likerttype response scale with 5 response options (strongly disagree $=1$, strongly agree $=5$ ). The total score ranged between 11 and 55 points and higher scores indicated more positive attitudes towards communication. The scale showed an adequate internal consistency $(\alpha=0.75)$ and excellent structural validity $(\mathrm{CFI}=0.99 ; \mathrm{TLI}=0.99$; $\mathrm{RMSEA}=0.01$ [95\% CI $=0.00-0.05]$ ), for the Spanish version.

Communication skills were assessed using the Spanish Healthcare Professionals Communication Skills Scale (HPC-SS; Leal-Costa et al., 2016). This self-administered, 18-item instrument uses a Likert-type response scale with 6 response options (almost never $=1$, to many times $=6$ ), and analyzes four dimensions: empathy, informative communication, respect, and social ability or assertiveness with an 
internal consistency in each dimension of $0.77,0.78,0.74$, and 0.65 , respectively.

Satisfaction with the simulation program was evaluated in Spanish with the High Fidelity Clinical Simulation Satisfaction Scale (ESSAF; Alconero-Camarero et al., 2016) which comprises 41 items: 3 open questions and 38 with a Likert-type response scale with 5 response options ( $1=$ totally disagree, $5=$ totally agree). The ESSAF evaluates 8 dimensions of satisfaction. In this study we used 3 of 8 the dimensions: utility $(\alpha=0.92)$, communication $(\alpha=0.92)$, and increased selfconfidence $(\alpha=0.92)$.

The script for the semi-structured telephone interviews was based on two axes (1) experience and satisfaction with the simulation program (How was your experience of the simulation program? and How did you feel when you participated in this type of program?); and (2) the perceived effects of the simulation program (What did you gain from the simulation program?, What factors do you think this training helped you to improve?, For you, what were the drawbacks of this type of training?, and To what extent was this simulation program useful to you?).

\subsection{Ethical considerations}

This study received approval from the University Bioethics Committee (UA-2018-10-24) and was carried out in accordance with the criteria established by the Declaration of Helsinki and the European Union's Good Clinical Practice Standards. Participation in the study was voluntary and therefore the students were informed that they could withdraw from the study at any time, despite their obligation to complete the simulation program as part of their required nursing degree assignments for the corresponding subjects they had enrolled in. Participation or non-participation in this work did not influence the students' degree program grades for these subjects in any way.

\subsection{Data collection}

In the first preparation session (phase 1) we administered an electronic questionnaire via Google Forms using the university's institutional internal platform to collect the sociodemographic variables and data about the students' perceived skills and attitudes towards communication using the evaluation scales described above. After implementation of the program, the same electronic questionnaire was administered again to measure the students' satisfaction with the simulation program. To encourage participation, we followed a standardized methodology in which we sent three reminders containing the questionnaire link, leaving one week between each email. The first wave was sent on the last day of the simulation program, and data were collected up to one month after its completion. In addition to the corresponding instrument items, both questionnaires included detailed information about the study, stated the voluntary nature of participation in the research, described the data treatment (which was solely for research purposes and was handled as a group, with complete confidentiality), and requested the students' express informed consent to their participation.

The qualitative data (phase 2) was collected from February to March 2020 when the students were completing their clinical practices. A theoretical sampling was carried out based on the percentiles of the students in terms of their perceived communication skills, obtained from the HPC-SS scale scores (Leal-Costa et al., 2016). Five of the selected students had communication skills variable percentiles under 50 and 6 had percentiles over 50 (Table 1). Because of movement and social contact restrictions related to the COVID-19 pandemic, one of the researchers contacted the selected students by telephone, explained the purpose of the study and arranged a date to conduct the interviews through a digital platform. With the students' prior consent, these interviews were recorded in a digital audio format to allow their verbatim transcription and subsequent analysis. Each interview lasted approximately $20 \mathrm{~min}$. All the students $(n=11)$ who were contacted for a
Table 1

Characteristics of the interviewees.

\begin{tabular}{llccl}
\hline ID & Sex & Age & $\begin{array}{l}\text { Communications skills } \\
\text { (range: 69-107) }\end{array}$ & Selection percentiles \\
\hline E4 & Female & 20 & 73 & P15 Communications skills \\
E1 & Female & 21 & 80 & P15 Communications skills \\
E2 & Female & 21 & 83 & P25 Communications skills \\
E3 & Female & 30 & 84 & P25 Communications skills \\
E5 & Male & 21 & 86 & P25 Communications skills \\
E7 & Female & 21 & 90 & P50 Communications skills \\
E9 & Female & 20 & 95 & P75 Communications skills \\
E8 & Female & 21 & 96 & P75 Communications skills \\
E6 & Female & 21 & 97 & P75 Communications skills \\
E11 & Female & 20 & 99 & P90 Communications skills \\
E10 & Male & 20 & 104 & P90 Communications skills \\
\hline
\end{tabular}

telephone interview agreed to participate voluntarily.

\subsection{Data analysis}

SPSS software (version 25) was used for all the statistical analyses (IBM Corp., Armonk, NY). We performed a descriptive analysis of the response frequency for each categorical item and calculated the mean and standard deviation $(M \pm S D)$ for the continuous variables. The normality of data was assessed using the Kolmogorov-Smirnov test with Lilliefors correction. Mann-Whitney $U$ tests were used to compare gender and mean satisfaction scores. Spearman tests (rho) were used to evaluate correlations between satisfaction, age, attitudes towards communication, and perceived communication skills.

The qualitative analysis was performed following the six-stage thematic analysis framework by Braun and Clarke (2006) by performing a triangulation process with the different data sets. The research team comprised three doctoral nurses with previous experience in conducting qualitative research. The results were analyzed by the whole team and a final consensus was reached on the most relevant data interpretations according to the data collected in the first part of the study. No computer software was used in our qualitative analyses.

\section{Results}

\subsection{Phase 1}

Of the 156 students who completed both the pre-and post-training questionnaires, $84 \%$ were female $(n=131)$. Their mean age was 22.85 years $(S D=5.29$; range $=20-48$ years $)$, and $96.80 \%(n=151)$ were Spanish. Most of the students had received specific training in communication skills during their undergraduate nursing training $(96.20 \% ; n=$ $150)$, and $18.60 \%(n=29)$ had also had this type of training outside of their degree course training. The students began the simulation program with high positive attitudes towards communication $(M=52.62$; $S D=$ 2.51 ) and a high perception of having adequate communication skills $(M=89.41 ; S D=2.52)$.

The scores for all the ESSAF dimensions were high (Table 2). The mean utility score was $58.69(S D=7.20$; range $=24-65)$; 14.03 for communication $(S D=1.99$; range $=3-15$; and for the increase in selfconfidence, it was $12.98(S D=2.33$; range $=3-15)$. All the responses exceeded 4 out of 5 points, and $95.5 \%$ of the students $(n=149)$ said the simulation "had improved their communication with patients". The items with the lowest satisfaction rates corresponded to the selfconfidence dimension, specifically, "The simulation promotes self-confidence" and "This practical increased my confidence" items, which had response rates of $78.2 \%$ and $79.5 \%$, respectively.

The Table 3 shows the relationships between the degree of satisfaction with socio-demographic variables (gender and age) and other factors related to the training program. After verifying the assumption that the data was non-normal, our analyses showed no relationship between the ESSAF and socio-demographic variables. There were significant 
Table 2

Descriptive data for the degree of satisfaction with the high-fidelity simulated experience $(n=156)$

\begin{tabular}{|c|c|c|}
\hline & $M(S D)$ & $\begin{array}{l}\text { Somewhat } \\
\text { agree/ } \\
\text { Totally agree } \\
n(\%)\end{array}$ \\
\hline Utility dimension (range: $13-65$ ) & $\begin{array}{l}58.69 \\
(7.20)\end{array}$ & - \\
\hline $\begin{array}{l}\text { The simulation is useful for assessing the clinical } \\
\text { situation of patients }\end{array}$ & $\begin{array}{l}4.54 \\
(0.67)\end{array}$ & $143(91.7)$ \\
\hline $\begin{array}{l}\text { The simulation has improved my ability to provide } \\
\text { care }\end{array}$ & $\begin{array}{l}4.58 \\
(0.71)\end{array}$ & $143(91.7)$ \\
\hline $\begin{array}{l}\text { The simulation helps you improve your } \\
\text { communication skills and ability to work with the } \\
\text { team }\end{array}$ & $\begin{array}{l}4.49 \\
(0.77)\end{array}$ & $140(89.8)$ \\
\hline $\begin{array}{l}\text { The simulation allowed us to effectively plan patient } \\
\text { care }\end{array}$ & $\begin{array}{l}4.29 \\
(0.87)\end{array}$ & $133(85.3)$ \\
\hline I have improved my technical skills & $\begin{array}{l}4.38 \\
(0.87)\end{array}$ & 134 (85.9) \\
\hline $\begin{array}{l}\text { I have strengthened my critical thinking and decision- } \\
\text { making skills }\end{array}$ & $\begin{array}{l}4.65 \\
(0.61)\end{array}$ & $147(94.3)$ \\
\hline $\begin{array}{l}\text { The simulation helped me assess the patient's } \\
\text { condition }\end{array}$ & $\begin{array}{l}4.51 \\
(0.68)\end{array}$ & $142(91)$ \\
\hline This experience has helped me prioritize care & $\begin{array}{l}4.53 \\
(0.68)\end{array}$ & $142(91)$ \\
\hline I have improved my communication with the team & $\begin{array}{l}4.38 \\
(0.82)\end{array}$ & $135(86.6)$ \\
\hline $\begin{array}{l}\text { I have improved my communication with patient } \\
\text { families }\end{array}$ & $\begin{array}{l}4.44 \\
(0.77)\end{array}$ & $138(87.4)$ \\
\hline I have improved my communication with patients & $\begin{array}{l}4.62 \\
(0.60)\end{array}$ & 149 (95.5) \\
\hline $\begin{array}{l}\text { Interacting with simulated experiences has improved } \\
\text { my clinical competence }\end{array}$ & $\begin{array}{l}4.53 \\
(0.69)\end{array}$ & $141(90.4)$ \\
\hline $\begin{array}{l}\text { I have learned from the mistakes I made during the } \\
\text { simulations }\end{array}$ & $\begin{array}{l}4.74 \\
(0.63)\end{array}$ & $147(94.2)$ \\
\hline Communication dimension (range: $3-15$ ) & $\begin{array}{l}14.03 \\
(1.9)\end{array}$ & - \\
\hline $\begin{array}{l}\text { The teacher was in charge of giving constructive } \\
\text { feedback }\end{array}$ & $\begin{array}{l}4.63 \\
(0.75)\end{array}$ & $143(91.7)$ \\
\hline $\begin{array}{l}\text { The analysis at the end of the session (debriefing) } \\
\text { helped me to reflect on the experience }\end{array}$ & $\begin{array}{l}4.72 \\
(0.68)\end{array}$ & $146(93.6)$ \\
\hline $\begin{array}{l}\text { The analysis at the end of the session (debriefing) } \\
\text { helped me to correct my own errors }\end{array}$ & $\begin{array}{l}4.68 \\
(0.70)\end{array}$ & $145(93)$ \\
\hline Increased self-confidence dimension (range: 3-15) & $\begin{array}{l}12.98 \\
(2.33)\end{array}$ & - \\
\hline The simulations promote self-confidence & $\begin{array}{l}4.26 \\
(0.94)\end{array}$ & $122(78.2)$ \\
\hline This type of practical has increased my confidence & $\begin{array}{l}4.23 \\
(0.92)\end{array}$ & 124 (79.5) \\
\hline General satisfaction of the sessions & $\begin{array}{l}4.49 \\
(0.72)\end{array}$ & $144(92.3)$ \\
\hline
\end{tabular}

correlations between the students' attitudes towards communication before the simulation training and the utility and communication dimensions of the ESSAF. The students' perceived communication skills before the simulation program were associated with the utility dimension of the ESSAF, but we found no correlations with the communication and self-confidence dimensions of the ESSAF (Table 3).

\subsection{Phase 2}

Eleven students, who had participated both in the simulation program and the first part of the study and who also met the theoretical sampling criteria participated in the second study phase (Table 1). Their mean age was 21.45 years $(S D=2.74$; range $=20-31$ years $)$ and $81.1 \%$ were women $(n=9)$. As shown in Table 4 and as described below, two main themes and four sub-themes emerged during the students' discourses.

\section{Theme 1: immersion in new teaching methodologies}

The students identified the simulation program as a novel
Table 3

Relation between the degree of satisfaction, sociodemographic variables and others related to the training program $(n=156)$.

\begin{tabular}{llll}
\hline & \multicolumn{2}{l}{ ESSAF dimensions } & \\
\cline { 2 - 4 } & Utility & Communication & Increased self-confidence \\
\hline Socio-demographics variables & & \\
Age $^{\text {a }}$ & -0.35 & -0.03 & -0.01 \\
Gender $^{b}$ & 1338.50 & 1600.50 & 1.549 .50 \\
Male $(M / S D)$ & $57.60(6.09)$ & $14.36(1.08)$ & $12.96(2.13)$ \\
Female $(M / S D)$ & $58.89(7.39)$ & $13.97(2.11)$ & $12.98(2.34)$ \\
Other variables $_{\text {Attitude }}{ }^{\mathrm{a}}$ & $0.24^{* *}$ & $0.16^{*}$ & \\
HPC-SS $^{\text {a }}$ & $0.18^{*}$ & 0.13 & 0.11 \\
\hline
\end{tabular}

Note: $\mathrm{M}=$ Average; $\mathrm{SD}=$ Standard deviation; ESSAF = Satisfaction Scale Questionnaire with High-Fidelity Clinical Simulation (Alconero-Camarero et al., 2016); Attitude = Spanish version of the Health Communication Attitude Scale (manuscript in process); HPC-SS $=$ Healthcare Professionals Communication Skills Scale (Leal-Costa et al., 2016).

${ }^{a}$ Rho de Spearman statistic.

b Mann-Whitney U statistic.

* $p<0.05$.

$p<0.01$.

Table 4

Extracted topics and sub-themes.

\begin{tabular}{ll}
\hline Themes & Sub-themes \\
\hline 1. Immersion in new teaching & $\begin{array}{l}1.1 \text { Empowerment in learning } \\
\text { methodologies }\end{array}$ \\
$\begin{array}{l}1.2 \text { Emotional management in the context of } \\
\text { the new methodology }\end{array}$ \\
$\begin{array}{l}\text { 2. Usefulness of the simulated } \\
\text { experience program }\end{array}$ & $\begin{array}{l}2.2 \text { Impact on a personal and professional } \\
\text { level }\end{array}$ \\
\hline
\end{tabular}

educational methodology that represented an evident change with respect to the methodologies they had encountered in their training up until that point. Although they recognized the value of the theoretical content, putting their knowledge into practice had allowed them to train their skills at another level.

\subsection{Empowerment in learning}

The interviewees recognized a change in their student roles and the advantages of actively participating in the learning process. This methodology forced them to investigate and mobilize new and different strategies by themselves, relying on collaborative teamwork and individual introspection to be able to progress through the simulation program. Likewise, they recognized debriefing as a key part of the learning process.

"I found it to be an effective way to learn, not only in the moment of doing the simulation ourselves, but also seeing [the simulations of] others" (E9);

"The debriefing forced you to be active because then you had to comment" (E10); "You didn't go to this practical [with] the same [feeling] as other [ones]. You went to this one with more enthusiasm, you were much more motivated [...]. While you saw the simulations [of others], you also thought about how you would do it" (E2).

\subsection{Emotional management when using the new methodology}

Inexperience led the students to experience stage fright, shame, uncertainty, anxiety, nerves, etc., which were all emotions that they had to identify and manage as part of their learning process. Despite having completed more than $1500 \mathrm{~h}$ of practical clinical experience, they had never had to take the lead in a care-giving process or resolution of a case. 
"At first, I didn't know what to say or do, but then I [started] controlling it" (E1); "It helped me feel less ashamed" (E5); "We had the pressure [that the practical] was assessable, and I was afraid of [disadvantaging] my class-mates if I did it wrong, but little by little, I managed [the process] and enjoyed and learned from the simulation" (E9).

\section{Theme 2: usefulness of the simulation program}

The interviewees highlighted the usefulness of the program to implement the knowledge they had acquired through their theoretical classes in a real and dynamic way. This allowed them to improve their use of different communication resources in interviews with patients.

"Communication techniques are learned from the beginning but putting them into practice was decisive [in helping me] to feel prepared" (E4); "it helped me to know what I should say and especially, how to handle silences." (E1).

At the time of the interview, the students were completing the last $300 \mathrm{~h}$ of their practical clinical experience. This allowed them to assess to what extent they could use the resources they had acquired during the simulation program to solve problems in real situations. Most of the interviewees had already experienced situations like those in the simulations.

"In the psychiatry practical I remembered these simulations and applied what I had learned" (E5); "In the pain unit, we had a lot of telephone contact and I was able to put into practice various techniques that I had learned in the simulation, especially when dealing with family members" (E7).

\subsection{Self-confidence and self-security}

The interviewees claimed that they had felt safer when faced with real situations because they had already trained and practiced them in a safe environment. In addition, previous experience increased their selfconfidence because they felt that they had clear tools to control the situations, which therefore increased their self-security when facing real situations.

"I feel more confident talking to patients and know what to say and what to be careful with [now]" (E6); "when we're faced with a real situation, we need to draw from experience and because we're new, having the opportunity to practice helps us a lot" (E4).

\subsection{Impact at the personal and professional levels}

The interviewees said that the simulation program had had a very positive impact on them at a personal level to allow them to get to know each other more, help them reflect upon their weaknesses and points for improvement, and to progress in terms of emotional competence. At a professional level it had increased their experience and therefore, helped them to acquire basic professional skills they could use in clinical practice, as reflected in the following examples:

"When I saw myself in the recordings and remembered what my colleagues told me, I reconsidered what things I had to work on... I'm more fluent [now] and control my nerves better" (E10).

\section{Discussion}

Using a mixed methodology, this current work allowed us to measure satisfaction levels and explore, in depth, the factors that affect the satisfaction of nursing students completing a high-fidelity simulation program with standardized patients as a teaching resource. MacLean et al. (2017) concluded, in their integrative review of the evidence for the use of simulated patient programs and their relationship with developing therapeutic communication skills among undergraduate and graduate nurses, that there was a bias towards quantitative research and the use of questionable tools and small sample sizes. Thus, they suggested that mixed-method studies with larger samples, valid tools, and rigorous qualitative protocols would be required to guarantee adequate triangulation of research results. Our students reported high satisfaction scores for the simulation program, similar to those in other programs that trained communication skills with standardized patients (Donovan and Mullen, 2019; Goh et al., 2016; Hsu et al., 2015; Jang et al., 2019; Johnson et al., 2020).

Almost all the students were satisfied with the usefulness of the simulation program, stating that "they had improved their communication with patients" or "had learned from mistakes they had made during the simulations". These feelings were also supported by most of the students in the second-phase interviews. The latter students were in clinical placements, thus giving us the opportunity to learn how the simulation program had impacted them in a real context (Goh et al., 2016). These students highlighted the usefulness of integrating theory into practice in realistic ways (Goh et al., 2016), as well as their perceived ability to transfer the new communication skills they had acquired from simulated experiential situations in similar real-life contexts (Carson and Harder, 2016). Indeed, Thomas and Mraz (2017) explored the transfer of experiences from simulations into the studentto-professional transition process and showed how the simulation and debriefing processes improved the ability of new graduates to make clinical decisions, solve problems, and use clinical reasoning in complex patient care situations. These results show how students perceive standardized patient simulation as an effective methodology to train communication skills in nursing students, thereby preparing them for future clinical practice (Øgård-Repål et al., 2018); this was one of the reasons why the students expressed high satisfaction towards such learning strategies.

In line with other studies (Alconero-Camarero et al., 2019; Swenty and Eggleston, 2011), the high level of student satisfaction with the communication dimension (which was related to the debriefing process) also stood out. The debriefing was recognized as an important part of the simulation program because it allowed the students to learn from their mistakes, reflect upon their experiences, and improve their performance and self-perceived competence (Dufrene and Young, 2014). According to our results, active participation increased the students' motivation to learn, which agrees with the findings of the meta-analysis by $\mathrm{Oh}$ et al. (2015), which also highlighted how student motivation positively influenced the knowledge and the acquisition of clinical skills. So, we can conclude that students positively recognize active methodologies such as simulation, which encourage their participation and personal reflection upon their learning. However, as suggested in a recent systematic review and meta-analysis (Lee et al., 2020), careful attention must be paid to the debriefing methods used so that they adequately impact learning outcomes. In this sense, implementing structured reflection processes, as we did in this current work, is key.

Regarding the self-confidence dimension, although the participants reported high satisfaction levels, a smaller portion (with respect to the other dimensions) agreed that the simulation program promoted selfconfidence and that their self-confidence had increased. As some students indicated in their interviews, this could be because some of the emotions they had faced in the simulation program, such as fear, shame, or uncertainty (Fraser and McLaughlin, 2019) made them feel insecure or less confident in their ability to address situations, despite them undertaking the program in a respectful student-centered environment that provided constructive feedback (Kang and Min, 2019). However, the students also indicated that they had subsequently felt safer when faced with real-life situations because they considered that their training had provided them with more personal resources and better emotional management abilities to cope with these situations. In this line, Schlegel 
et al. (2012) found that providing more opportunities for students to practice their communication skills in high-risk conversations improved their self-confidence and reduced their anxiety levels in real-world clinical settings. Thus, this increased student perception of selfconfidence and self-security was one of the main reasons why communication skills training through a simulation program with standardized patients should be started from the earliest stages of health profession curricula (Donovan and Mullen, 2019; Labrague et al., 2018; Sarikoc et al., 2017).

Finally, our results showed that students with more positive attitudes towards communication and who perceived themselves as having better communication skills before starting the training, were also more satisfied with the utility of the simulation program. In this sense, Ishikawa et al. (2014) suggested that positive attitudes may influence the process of the learning. Therefore, we believe that it would be important to implement previous training in communication skills before simulation programs, thereby increasing their overall satisfaction levels. This previous approach to the content, focused on increasing skills and attitudinal competencies, will later allow students to get more out of the simulation training programs, especially in terms of usefulness of its usefulness.

\subsection{Limitations}

First, we used a convenience sample and only studied a singleuniversity cohort. Studies in other centers with samples of nursing students that are representative at the national level must be carried out for these results to be generalizable. Second, this current work did not include a control group. Communication skills are part of the general skills students require to perform their future professional duties and so they must all receive this training as part of their nursing undergraduate degrees in order to acquire these skills. Thus, it would be unethical to randomly choose a control group which would either not be trained in these skills or that would receive another type of less-adequate training. Finally, the interviews in the qualitative study were carried out when the students were completing their clinical practices and were able to put what they had learned to use almost immediately, perhaps leading to a memory bias regarding their program experiences.

\subsection{Conclusions}

In conclusion, nursing students showed high levels of satisfaction with the high-fidelity simulation program with standardized patients we implemented. In terms of perceived usefulness, students reported feeling that the simulation program had helped them feel more self-confident and safer and it had had a positive effect on a personal and professional level. Finally, the immersion aspect of this methodology allowed them to improve their skills, mobilize new strategies to interact with patients, and manage their emotions as a part of their learning process.

\subsection{Implications for practice}

The high levels of student satisfaction, interest, and motivation with the high-fidelity simulation program we implemented with standardized patients, justifies the need for health training centers to invest in tools and human resources aimed at developing this type of program. These programs should be designed to help students acquire non-technical skills with a high psycho-emotional and attitudinal load which can later be used in clinical settings. Moreover, knowledge of the specific factors that the students identified as key elements in their satisfaction with the simulation program will allow us to improve them to increase these levels of satisfaction and the results obtained, if possible. Finally, related to simulation research, it would be advisable to carry out longitudinal studies that examine the degree of transfer of the knowledge acquired by students from these programs into clinical practice and to connect the Kirkpatrick and Kirkpatrick (2006) levels 1, 2, and 3 outcomes with health outcomes (level 4).

\section{CRediT authorship contribution statement}

All authors should have made substantial contributions to all of the following: (1) the conception and design of the study and acquisition of data, and analysis and interpretation of data, (2) drafting the article or revising it critically for important intellectual content, (3) final approval of the version to be submitted.

\section{Author statement}

This manuscript has not been published, nor is under consideration by any other journal.

\section{Funding sources}

This research was funded by I3CE-Networking Programme for research in university teaching, Institute of Education Sciences of the University of Alicante. Editions 2018-19 (ID: XARXES-I3CE-2019-4344) and 2019-20 (XARXES-I3CE-2019-4755).

\section{Declaration of competing interest}

None.

\section{References}

Alconero-Camarero, A.R., Gualdrón-Romero, A., Sarabia-Cobo, C.M., Martinez-Arce, A, 2016. Clinical simulation as a learning tool in undergraduate nursing: Validation of a questionnaire. Nurs Educ. Today 39, 128-134.

Alconero-Camarero, A.R., Sarabia-Cobo, C.M., González-Gómez, S., IbánezRementería, I., Alvarez-García, M.P., 2019. Descriptive study of the satisfaction of nursing degree students in high-fidelity clinical simulation practices. Enferm Clínica 30 (6), 303-410. https://doi.org/10.1016/j.enfcli.2019.07.007.

Alsaad, A.A., Davuluri, S., Bhide, V.Y., Lannen, A.M., Maniaci, M.J., 2017. Assessing the performance and satisfaction of medical residents utilizing standardized patient versus mannequin-simulated training. Adv Medical Educ Practice 8, 481-486. https://doi.org/10.2147/AMEP.S134235.

Braun, V., Clarke, V. 2006. Using thematic analysis in psychology. Qual Res Psychol, 3 (2), 77-101. doi:10.1191 / 1478088706qp063oa.

Bremner, M., Aduddell, K., Bennett, F., VanGeest, J., 2006. The use of human patient simulators: best practice with novice nursing students. Nurse Educ. 31 (4), 170-174. https://doi.org/10.1097/00006223-200607000-00011.

Calamassi, D., Nannelli, T., Guazzini, A., Rasero, L., Bambi, S. 2016. High fidelity simulation experience in emergency settings: doctors and nurses satisfaction levels. Acta Biomed 87(4-S), 38-50.

Cant, R.P., Cooper, S.J., 2010. Simulation-based learning in nurse education: systematic review. J Adv Nursing 66 (1), 3-15.

Carson, P.P., Harder, N., 2016. Simulation use within the classroom: recommendations from the literature. Clin Simulation Nursing 12 (10), 429-437. https://doi.org/ 10.1016/j.ecns.2016.03.009.

Donovan, L.M., Mullen, L.K., 2019. Expanding nursing simulation programs with a standardized patient protocol on therapeutic communication. Nurse Educ Practice 38, 126-131. https://doi.org/10.1016/j.nepr.2019.05.015.

Dufrene, C., Young, A., 2014. Successful debriefing - best methods to achieve positive learning outcomes: a literature review. Nurse Educ. Today 34 (3), 372-376. https:// doi.org/10.1016/j.nedt.2013.06.026.

Fey, M.K., Jenkins, L.S., 2015. Debriefing practices in nursing education programs: results from a national study. Nurse Educ Perspect 36 (6), 361-366. https://doi.org/ 10.5480/14-1520.

Fraser, K., McLaughlin, K., 2019. Temporal pattern of emotions and cognitive load during simulation training and debriefing. Med Teach 41 (2), 184-189. https://doi. org/10.1080/0142159X.2018.1459531.

Goh, Y.-S., Selvarajan, S., Chng, M.-L., Tan, C.-S., Yobas, P., 2016. Using standardized patients in enhancing undergraduate students' learning experience in mental health nursing. Nurse Educ. Today 45, 167-172. https://doi.org/10.1016/j. nedt.2016.08.005.

Hegland, P.A., Aarlie, H., Strømme, H., Jamtvedt, G., 2017. Simulation-based training for nurses: systematic review and meta-analysis. Nurse Educ. Today 54, 6-20. https:// doi.org/10.1016/j.nedt.2017.04.004.

Hsu, L.-L., Chang, W.-H., Hsieh, S.-I., 2015. The effects of scenario-based simulation course training on nurses' communication competence and self-efficacy: a randomized controlled trial. J. Prof. Nurs. 31 (1), 37-49. https://doi.org/10.1016/j. profnurs.2014.05.007.

Ishikawa, H., Eto, M., Kitamura, K., Kiuchi, T., 2014. Resident physicians' attitudes and confidence in communicating with patients: a pilot study at a Japanese university 
hospital. Patient Educ. Couns. 96 (3), 361-366. https://doi.org/10.1016/j. pec.2014.05.012.

Jang, K.I., Yoo, Y.S., Roh, Y.S., 2019. Development and effectiveness of an oncology nursing standardized patient simulation program for nursing students. J Korean Adu Nurs 31 (6), 595-604. https://doi.org/10.7475/kjan.2019.31.6.595.

Johnson, K. V., Scott, A. L., \& Franks, L. 2020. Impact of standardized patients on first semester nursing students self-confidence, satisfaction, and communication in a simulated clinical case. SAGE Open Nursing, 6, 2377960820930153. doi.: https://doi. org $/ 10.1177 / 2377960820930153$.

Kang, S.J., Min, H.Y., 2019. Psychological safety in nursing simulation. Nurse Educ. 44 (2), E6-E9. https://doi.org/10.1097/NNE.0000000000000571.

Kim, J., Park, J.H., Shin, S., 2016. Effectiveness of simulation-based nursing education depending on fidelity: a meta-analysis. BMC Medical Educ 16, 152. https://doi.org/ 10.1186/s12909-016-0672-7.

Kirkpatrick, D., Kirkpatrick, J., 2006. Evaluating Training Programs: The Four Levels. Berrett-Koehler Publishers, San Francisco.

Labrague, L.J., McEnroe-Petitte, D.M., Fronda, D.C., Obeidat, A.A., 2018. Interprofessional simulation in undergraduate nursing program: an integrative review. Nurse Educ. Today 67, 46-55. https://doi.org/10.1016/j.nedt.2018.05.001.

Langille, D.B., Kaufman, D.M., Laidlaw, T.A., Sargeant, J., MacLeod, H., 2001. Faculty attitudes towards medical communication and their perceptions of students' communication skills training at Dalhousie university. Med. Educ. 35 (6), 548-554.

Lapkin, S., Levett-Jones, T., Bellchambers, H., Fernandez, R., 2010. Effectiveness of patient simulation manikins in teaching clinical reasoning skills to undergraduate nursing students: a systematic review. Clinical Simulation in Nursing 6 (6), e207-e222. https://doi.org/10.1016/j.ecns.2010.05.005.

Leal-Costa, C., Tirado-González, S., Rodríguez-Marín, J., vander-Hofstadt-Román, C.J., 2016. Psychometric properties of the health professionals communication skills scale (HP-CSS). Int. J. Clin. Heal. Psychol 16, 76-86. https://doi.org/10.1016/j. ijchp.2015.04.001.

Lee, J., Lee, H., Kim, S., Choi, M., Ko, I.S., Bae, J., Kim, S.H., 2020. Debriefing methods and learning outcomes in simulation nursing education: A systematic review and meta-analysis. Nurse Educ. Today 87, 104345. https://doi.org/10.1016/j. nedt.2020.104345.

Luctkar-Flude, M., Wilson-Keates, B., Larocque, M., 2012. Evaluating high-fidelity human simulators and standardized patients in an undergraduate nursing health assessment course. Nurs. Educ. Today 32, 448-452. https://doi.org/10.1016/j. nedt.2011.04.011.

MacLean, S., Kelly, M., Geddes, F., Della, P., 2017. Use of simulated patients to develop communication skills in nursing education: an integrative review. Nurs. Educ. Today 48, 90-98. https://doi.org/10.1016/j.nedt.2016.09.018.

Mullan, B.A., Kothe, E.J., 2010. Evaluating a nursing communication skills training course: the realtionships between self-rated ability, satisfaction, and actual performance. Nurse Educ. Pract. 10 (6), 374-378. https://doi.org/10.1016/j. nepr.2010.05.007.
Øgård-Repål, A., De Presno, Å.K., Fossum, M., 2018. Simulation with standardized patients to prepare undergraduate nursing students for mental health clinical practice: an integrative literature review. Nurse Educ. Today 66, 149-157. https:// doi.org/10.1016/j.nedt.2018.04.018.

Oh, P., Jeon, K.D., Koh, M.S., 2015. The effects of simulation-based learning using standardized patients in nursing students: a meta-analysis. Nurs. Educ. Today 35 (5), e6-e15. https://doi.org/10.1016/j.nedt.2015.01.019.

Olaussen, C., Heggdal, K., Tvedt, C.R., 2020. Elements in scenario-based simulation associated with nursing students' self-confidence and satisfaction: a cross-sectional study. Nurs Open 7 (1), 170-179. https://doi.org/10.1002/nop2.375.

Raurell-Torredà, M., Llauradó-Serra, M., Lamoglia-Puig, M., Rifà-Ros, R., Díaz-Agea, J., García-Mayor, S., Romero-Collado, A., 2020. Standardized language systems for the design of high-fidelity simulation scenarios: a delphi study. Nurs. Educ. Today 86, 104319. https://doi.org/10.1016/j.nedt.2019.104319.

Sarabia-Cobo, C.M., Alconero-Camarero, A.R., Lavín-Alconero, L., Ibáñez-Rementería, I., 2016. Assessment of a learning intervention in palliative care based on clinical simulations for nursing students. Nurs. Educ. Today 45, 219-224. https://doi.org/ 10.1016/j.nedt.2016.08.014.

Sarikoc, G., Ozcan, C.T., Elcin, M., 2017. The impact of using standardized patients in psychiatric cases on the levels of motivation and perceived learning of the nursing students. Nurs. Educ. Today 51, 15-22. https://doi.org/10.1016/j. nedt.2017.01.001.

Schlegel, C., Woermann, U., Shaha, M., Rethans, J.J., van der Vleuten, C., 2012. Effects of communication training on real practice performance: a role-play module versus a standardized patient module. J. Nurs. Educ. 51 (1), 16-22. https://doi.org/10.3928/ 01484834-20111116-02.

Swenty, C.F., Eggleston, B.M., 2011. The evaluation of simulation in a baccalaureate nursing program. Clinical Simulation Nursing 7 (5), e181-e187. https://doi.org/ 10.1016/j.ecns.2010.02.006.

Thomas, C.M., Mraz, M.A., 2017. Exploration into how simulation can effect new graduate transition. Clinical Simulation in Nursing 13 (10), 465-470.

Walker, S., Rossi, D., Anastasi, J., Gray-Ganter, G., Tennent, R., 2016. Indicators of undergraduate nursing students' satisfaction with their learning journey: an integrative review. Nurse Educ. Today 43 (40), 48. https://doi.org/10.1016/j. nedt.2016.04.011.

Webster, D., 2014. Using standardized patients to teach therapeutic communication in psychiatric nursing. Clinical Simulation in Nursing 10 (2), e81-e86. https://doi.org/ 10.1016/j.ecns.2013.08.005.

Willhaus, J., 2016. Simulation basics: how to conduct a high-fidelity simulation. AACN Adv Crit Care 27 (1), 71-77. https://doi.org/10.4037/aacnacc2016569.

Escribano, S., Juliá-Sanchis, R., García-Sanjuán, S., Congost-Maestre, N., CabañeroMartínez, M.J., 2021. Psychometric properties of the Attitudes Towards Medical Communication Scale in nursing students. Peer J. (Manuscript Accepted).

Yuan, H.B., Williams, B.A., Fang, J.B., Ye, Q.H., 2012. A systematic review of selected evidence on improving knowledge and skills through high-fidelity simulation. Nurs. Educ. Today 32 (3), 294-298. https://doi.org/10.1016/j.nedt.2011.07.010. 